\title{
BMJ Open Is subjective well-being independently associated with mortality? A 14-year prospective cohort study in a representative sample of 25139 US men and women
}

Steven D Barger (D), Timothy W Broom, Michael V Esposito, Taylor S Lane

To cite: Barger SD, Broom TW, Esposito MV, et al. Is subjective well-being independently associated with mortality? A 14-year prospective cohort study in a representative sample of 25139 US men and women. BMJ Open 2020;10:e031776. doi:10.1136/ bmjopen-2019-031776

- Prepublication history and additional material for this paper are available online. To view these files, please visit the journal online (http://dx.doi. org/10.1136/bmjopen-2019031776).

Received 17 May 2019 Revised 22 November 2019 Accepted 02 December 2019

D) Check for updates

(c) Author(s) (or their employer(s)) 2020. Re-use permitted under CC BY-NC. No commercial re-use. See rights and permissions. Published by BMJ.

Psychological Sciences, Northern Arizona University, Flagstaff, Arizona, USA

Correspondence to Dr Steven D Barger; steven.barger@nau.edu

\section{ABSTRACT}

Objectives To examine whether the inverse association of subjective well-being with mortality is independent of selfrated health and socioeconomic status in healthy adults.

Design A population-based prospective cohort study based on an in-person interview. Cox regression was used to examine mortality hazards for happiness alone and for a standardised summary well-being measure that included happiness, life satisfaction and negative emotions. Using prespecified analyses, we first adjusted for age and then additionally adjusted for self-rated health and then race/ ethnicity, marital status, smoking and socioeconomic status.

Setting Probability sample of adult US residents interviewed in their homes in 2001.

Participants 25139 adults free of cardiovascular disease and cancer at baseline.

Primary outcome measure All-cause mortality 14 years after the baseline interview as assessed by probabilistic matching using the National Death Index.

Results Age-adjusted unhappiness was associated with mortality (HR 1.27; 95\% Cl 1.11 to $1.45, \mathrm{p}=0.001$ ) but the association attenuated after adjusting for self-rated health (HR 1.01; 95\% Cl 0.88 to 1.16, $p=0.85$ ). A similar pattern was seen for the summary well-being measure in fully adjusted models (HR 1.00; 95\% Cl 0.99 to $1.00, \mathrm{p}=0.30$ ). In contrast, self-rated health was strongly associated with mortality. In the fully adjusted model with the summary well-being measure the hazards for good, very good and excellent self-rated health were $0.71(95 \% \mathrm{Cl} 0.62$ to 0.80 , $\mathrm{p}<0.001), 0.63$ (95\% Cl 0.55 to $0.71, \mathrm{p}<0.001)$ and 0.45 (95\% Cl 0.39 to $0.51, \mathrm{p}<0.001)$, respectively.

Conclusions In this representative sample of US adults, the association between well-being and mortality was strongly attenuated by self-rated health and to a lesser extent socioeconomic status.

\section{INTRODUCTION}

A very large study of UK women found that unhappiness was associated with increased mortality risk but also showed that the association was eliminated when statistically controlling for self-rated health. ${ }^{1}$ Thus, it
Strengths and limitations of this study

- Large, diverse probability sample of US adults with a large number of mortality events.

- Multiple well-being operations.

- The study did not assess meaning and purpose in life, another well-being facet.

appears that perceived health status, rather than happiness per se, is most strongly associated with longevity. However, whether this finding generalises to women outside the UK or whether it applies to men is unknown. ${ }^{2}$ The primary goal of this study is to examine whether unhappiness is associated with mortality risk and whether this association is eliminated when statistically controlling for self-rated health. We replicate Liu et $a l^{1}$ by examining this pattern in a populationbased US sample of women and extend that study by examining whether this association exists for US men. This primary study goal and analysis plan were preregistered at the Center for Open Science in December 2018 (https://osf.io/jxruq).

The second goal of this study is to evaluate whether a broader well-being assessment independently predicts mortality. To provide a stronger test of the claim that well-being is inversely associated with mortality, we also examine a well-being measure that includes happiness, life satisfaction and items assessing negative emotions. ${ }^{3}$ Happiness and life satisfaction comprise two of three major wellbeing domains ${ }^{4}$ and negative emotions are also important for well-being assessment. ${ }^{5}$ This aggregated measure may provide a more reliable indicator of subjective wellbeing, ${ }^{67}$ is similar to other aggregated wellbeing measures ${ }^{68}$ and provides a sensitivity 
Open access

Table 1 Baseline participant characteristics* 2001 US National Health Interview Survey

\begin{tabular}{|c|c|c|c|c|c|c|}
\hline Characteristic & Total & & Alive & & Deceased & \\
\hline Participants, no & 25139 & & 22143 & & 2996 & \\
\hline Age year, mean (SE) & 42.0 & $(0.10)$ & 39.8 & $(0.10)$ & 61.7 & $(0.40)$ \\
\hline Female sex, \% (no) & 51.7 & $(14084)$ & 51.7 & (12 421) & 51.5 & (1663) \\
\hline Male sex, \% (no) & 48.3 & (11 055) & 48.3 & $(9722)$ & 48.5 & (1333) \\
\hline \multicolumn{7}{|l|}{ Race/ethnicity, \% (no) } \\
\hline Hispanic & 11.8 & (4673) & 12.0 & $(4217)$ & 10.3 & (456) \\
\hline White (non-Hispanic) & 71.7 & (15 925) & 71.5 & $(13947)$ & 73.4 & (1978) \\
\hline Black (non-Hispanic) & 11.8 & (3561) & 11.7 & (3091) & 12.4 & $(470)$ \\
\hline Other (non-Hispanic) & 4.7 & $(980)$ & 4.8 & (888) & 3.8 & (92) \\
\hline \multicolumn{7}{|l|}{ Marital status, \% (no) } \\
\hline Unmarried/widowed/divorced/separated & 35.7 & $(11567)$ & 34.7 & (9833) & 44.6 & (1734) \\
\hline Married or cohabitating & 64.3 & $(13572)$ & 65.3 & $(12310)$ & 55.4 & $(1262)$ \\
\hline \multicolumn{7}{|l|}{ Education level, \% (no) } \\
\hline$<9$ th grade & 16.5 & $(4856)$ & 14.9 & $(3821)$ & 30.9 & (1035) \\
\hline High school & 29.1 & $(7107)$ & 28.8 & $(6183)$ & 32.2 & (924) \\
\hline Some college & 30.0 & (7345) & 30.8 & (6706) & 22.6 & (639) \\
\hline College graduate or higher & 24.4 & $(5831)$ & 25.5 & (5433) & 14.2 & (398) \\
\hline \multicolumn{7}{|l|}{ Home tenure, \% (no) } \\
\hline Owned/being purchased & 69.0 & (15 262) & 68.6 & (13 297) & 72.5 & (1965) \\
\hline Rent/other/do not know & 31.0 & $(9877)$ & 31.4 & $(8846)$ & 27.5 & (1031) \\
\hline \multicolumn{7}{|l|}{ Workforce status, \% (no) } \\
\hline Working & 72.1 & (17 640) & 76.1 & $(16$ 607) & 36.9 & (1033) \\
\hline Retired & 9.7 & $(2781)$ & 5.9 & (1439) & 42.9 & (1342) \\
\hline Unemployed & 14.1 & (3572) & 14.0 & (3119) & 14.7 & (453) \\
\hline Never worked & 4.0 & (1125) & 3.9 & $(957)$ & 5.5 & (168) \\
\hline Unknown & 0.1 & $(21)$ & 0.1 & $(21)$ & 0.0 & (0) \\
\hline \multicolumn{7}{|l|}{ Smoker, \% (no) } \\
\hline No & 76.6 & (19 181) & 77.0 & (16 976) & 72.8 & (2205) \\
\hline Yes & 23.4 & (5958) & 23.0 & $(5167)$ & 27.2 & (791) \\
\hline
\end{tabular}

Self-rated health, \% (no)

\begin{tabular}{lllllll}
\hline Poor & 1.4 & $(422)$ & 1.0 & $(274)$ & 4.9 & $(148)$ \\
\hline Fair & 6.2 & $(1837)$ & 5.2 & $(1337)$ & 15.4 & $(500)$ \\
\hline Good & 22.9 & $(6013)$ & 21.7 & $(5010)$ & 32.9 & $(1003)$ \\
\hline Very good & 34.4 & $(8542)$ & 34.9 & $(7685)$ & 30.1 & $(857)$ \\
\hline Excellent & 35.1 & $(8325)$ & 37.1 & $(7837)$ & 16.7 & $(488)$ \\
Happiness, \% (no) & & & & & & \\
$\quad$ None/a little/some of the time & 20.0 & $(5467)$ & 19.5 & $(4695)$ & 24.1 & $(772)$ \\
$\quad$ Most of the time & 63.3 & $(15337)$ & 64.0 & $(13663)$ & 57.1 & $(1674)$ \\
All of the time & 16.7 & $(4335)$ & 16.4 & $(3785)$ & 18.7 & $(550)$ \\
Life satisfactiont, \% (no) & & & & & & $(50)$ \\
$\quad$ Very dissatisfied & 0.9 & $(243)$ & 0.8 & $(193)$ & 1.7 & $(182)$ \\
$\quad$ Dissatisfied & 4.4 & $(1271)$ & 4.3 & $(1089)$ & 5.4 & $(1580)$ \\
$\quad$ Satisfied & 49.7 & $(12990)$ & 49.4 & $(11410)$ & 51.7 & $(158)$ \\
$\quad$ Very satisfied & 44.7 & $(10543)$ & 45.2 & $(9385)$ & 40.3 & $(1158)$ \\
$\quad$ Missing & 0.4 & $(92)$ & 0.3 & $(66)$ & 0.9 & $(26)$ \\
\hline
\end{tabular}




\begin{tabular}{|c|c|c|c|c|c|c|}
\hline Characteristic & \multicolumn{2}{|l|}{ Total } & \multicolumn{2}{|l|}{ Alive } & \multicolumn{2}{|c|}{ Deceased } \\
\hline \multicolumn{7}{|c|}{$\begin{array}{l}\text { Negative affect items } \dagger \text {, past } 30 \text { days, } \\
\text { mean (SE) }\end{array}$} \\
\hline Sad & 0.4 & $(0.007)$ & 0.4 & $(0.007)$ & 0.5 & $(0.020)$ \\
\hline Nervous & 0.6 & $(0.008)$ & 0.6 & (0.009) & 0.6 & $(0.024)$ \\
\hline Restless & 0.6 & (0.009) & 0.6 & $(0.009)$ & 0.6 & $(0.023)$ \\
\hline Hopeless & 0.2 & $(0.005)$ & 0.2 & $(0.005)$ & 0.2 & $(0.015)$ \\
\hline Everything is an effort & 0.5 & (0.009) & 0.5 & $(0.009)$ & 0.5 & $(0.021)$ \\
\hline Worthless & 0.2 & $(0.005)$ & 0.2 & (0.005) & 0.2 & $(0.014)$ \\
\hline
\end{tabular}

Data source: US National Center for Health Statistics.

${ }^{*}$ Participants who reported a prior diagnosis of heart attack, coronary heart disease, stroke or cancer were excluded. All percentages are weighted to represent the civilian non-institutionalised population of the United States. Mortality was ascertained through 31 December 2015. †Sample size is slightly smaller with life satisfaction ( $n=25047)$ and negative affect items $(n=24875)$.

test for the subjective well-being/mortality association. Although a meta-analytic review found evidence of an association between subjective well-being and survival, they also found evidence of small sample bias, that is, smaller studies reported larger associations between wellbeing and survival. ${ }^{4}$ Thus, additional studies with larger samples are desirable. Finally, in order to affirm subjective well-being as a survival determinant, it should predict mortality independent of self-rated health and it should do so independent from other established mortality determinants such as socioeconomic status (SES). We, therefore, statistically adjust for several SES indicators including work force status, education and home ownership.

\section{METHODS}

We analysed National Health Interview Survey (NHIS) data that were linked to the National Death Index (NDI). Specifically, our study participants included 31355 adults who participated in the 2001 US NHIS. ${ }^{9}$ The NHIS is an annual in-person survey of a probability sample of noninstitutionalised US residents. ${ }^{10}$ All participants provided informed consent. The response rate for sample adults conditional on family response rates was $73.8 \% .^{11}$
The National Center for Health Statistics ascertained mortality among these NHIS participants through 31 December 2015 via the NDI ${ }^{12}$ and a public use mortality file describing vital status that was released in February 2019 .

To minimise the influence of poor health causing both low well-being and elevated mortality risk, we restricted our analyses to those who were free of diagnosed major chronic diseases at baseline $(\mathrm{n}=25705),{ }^{4}$ that is, cancer and cardiovascular diseases (myocardial infarction, stroke and any coronary heart disease). These conditions were reported by the participants and we did not exclude those reporting risk factors such as diabetes and hypertension. The sample was further reduced when including only those with complete covariate data $(n=25$ 139; 2996 deaths). All survey assessments, including diagnosed chronic diseases, were assessed at the baseline interview and mortality was assessed over the next 14 years. Analyses using the combined well-being measure are based on a sample of 24800 (2918 deaths). This study did not require human subjects review because it involved secondary analysis of publicly available data lacking identifying information.

Table 2 Crude all-cause mortality rates (per 10 000) by happiness and self-rated health: 2001 US National Health Interview Survey

\begin{tabular}{|c|c|c|c|c|c|c|c|}
\hline \multirow[t]{2}{*}{ Happiness } & \multirow[b]{2}{*}{ Rate } & \multirow[b]{2}{*}{$95 \% \mathrm{CI}$} & \multirow[b]{2}{*}{ Deaths } & \multicolumn{3}{|c|}{ Self-rated health } & \multirow[b]{2}{*}{ Deaths } \\
\hline & & & & & Rate & $95 \% \mathrm{Cl}$ & \\
\hline None of the time & 7.5 & (5.6 to 10.1$)$ & 52 & Poor & 13.5 & (11.6 to 15.8 ) & 148 \\
\hline A little & 6.7 & (5.7 to 8.1 ) & 146 & Fair & 10.0 & (9.2 to 10.9 ) & 500 \\
\hline Some of the time & 5.1 & (4.7 to 5.5 ) & 574 & Good & 6.2 & (5.8 to 6.6 ) & 1003 \\
\hline Most of the time & 4.1 & (3.9 to 4.4 ) & 1674 & Very good & 4.0 & (3.7 to 4.3 ) & 857 \\
\hline All of the time & 5.1 & (4.6 to 5.6 ) & 550 & Excellent & 2.3 & (2.1 to 2.6 ) & 488 \\
\hline
\end{tabular}

Data source: US National Center for Health Statistics. 


\section{Patient and public involvement}

Patients were not involved in the design or conduct of this study. There is no plan to disseminate the results to the participants.

\section{Subjective well-being assessments}

Participants were asked 'During the past 30 days, how often did you feel happy?' Response options were all, most, some, a little or none of the time. This item was used for the primary study question regarding happiness and mortality. For the broader well-being measure, we also included responses to a life satisfaction question and six negative emotion questions. Life satisfaction was assessed by asking 'In general, how satisfied are you with your life? Would you say very satisfied, satisfied, dissatisfied or very dissatisfied?' Negative emotion questions were assessed by asking 'During the past 30 days, how often did you feel...' (1) so sad that nothing could cheer you up; (2) nervous; (3) restless or fidgety; (4) hopeless; (5) that everything was an effort; (6) worthless. Response options were all, most, some, a little or none of the time. Although these items can be used to classify probable serious mental illness ${ }^{13}$ here they are used to capture unpleasant affect, a recommended practice for subjective well-being assessment. ${ }^{5}$ We incorporated all negative emotion items along with happiness and life satisfaction into a single wellbeing index. Specifically, each item was standardised and summed. This aggregate index had good internal consistency (Cronbach's alpha=0.86), which was higher than a two-item index of happiness and life satisfaction (alpha $=0.63$ ). As a sensitivity analysis we also report fully adjusted hazards for a well-being index that included only happiness and life satisfaction and for life satisfaction and negative affect separately.

For the primary study question, we compared those who were happy all of the time (referent) to those who were happy most of the time and to those who were unhappy (ie, happy none, a little, and some of the time). This closely parallels the largest published study of happiness and well-being in women. ${ }^{1}$

Using age as the time scale, ${ }^{14} 15$ we used Cox models to estimate survival HRs for unhappiness, first adjusting for age by stratifying on 5-year age cohort ${ }^{16} 17$ and then adding self-rated health (indicator variables for poor/fair, good, very good and excellent health), followed by race/ ethnicity (white, black, Hispanic, other non-Hispanic) and other powerful mortality determinants including being married, workforce status (unemployed, never worked, retired, working), education, home ownership and current smoking (yes/no). The single four-category education variable met an interval assumption ${ }^{18}$ and was therefore modelled as a single variable rather than as separate indicators.

Education, workforce status and home ownership capture diverse elements of SES and they represent important potential confounders of the relationship between well-being and mortality. Self-rated health was entered after age because the largest study to date found self-rated health to be the 'key characteristic' attenuating the association between happiness and mortality. ${ }^{1}$ Race and ethnicity are relative weakly associated with subjective well-being ${ }^{19}$ but are strongly associated with mortality ${ }^{20}$ and thus were included as covariates. This analytical approach was specified a priori (see Introduction) - no other covariates were planned or evaluated. These analyses were repeated using the aggregated wellbeing measure, which were included as a sensitivity analysis and were not prespecified. We used StataMP V.15.1 (Stata Corp) incorporating the complex survey design in all estimates.

We examined the proportional hazards assumption for both sets of study questions by testing the interaction term for time and happiness and time and aggregated well-being, respectively. The happiness interaction term indicated that the proportional hazards assumption was satisfied. Proportional hazards for the aggregated wellbeing analyses were satisfied by additionally stratifying on current smoking status. Evaluation of squared predicted scores and graphical evaluation of residuals provided additional evidence for adequately specified Cox models.

We report several additional analyses in response to editorial feedback. To disentangle the relative contributions of self-rated health versus happiness for mortality risk, we examine mortality HRs for self-rated health within happiness categories and happiness within selfrated health categories. We also report models that evaluate life satisfaction and negative affect separately as well happiness HRs after adjusting singly for each prespecified covariate other than self-rated health. The latter clarifies the extent to which self-rated health can be considered the 'key characteristic' that attenuates the happiness/ mortality association in these data.

\section{RESULTS}

Demographic and well-being information for the sample are in table 1 . Crude mortality rates by happiness and by self-rated health are provided in table 2. The correlation between the three-level happiness variable and self-rated health was 0.21 (95\% CI 0.19 to 0.22 ).

Age-adjusted unhappiness was associated with greater mortality risk relative to those who were happy all of the time (HR 1.27; 95\% CI 1.11 to 1.45 ) whereas participants happy most of the time were similar to those happy all of the time (HR 0.96; $95 \%$ CI 0.86 to 1.08). Being unhappy was no longer associated with mortality when adding self-rated health to the model (HR 1.01; 95\% CI 0.88 to 1.16), a pattern that persisted after adjustment for the remaining covariates (HR 0.97; 95\% CI 0.85 to 1.11 ) (table 3). Age-adjusted unhappiness was associated with increased mortality risk for women and men separately. Again, adding self-rated health to the model reduced the HRs for both groups and this persisted after including the remaining covariates (table 4). In contrast, good, very good and excellent self-rated health were associated with substantially reduced mortality risk in the fully adjusted 
Table 3 Happiness and all-cause mortality HRs $(95 \% \mathrm{Cl})$ before and after adjustment for self-rated health and sociodemographic variables $(n=25139)$

\begin{tabular}{|c|c|c|c|c|c|c|}
\hline & Model 1 & & Mod & & Model 3 & \\
\hline & HR & $95 \% \mathrm{Cl}$ & HR & $95 \% \mathrm{Cl}$ & HR & $95 \% \mathrm{Cl}$ \\
\hline \multicolumn{7}{|l|}{ Happiness } \\
\hline Happy all of the time & (Referent) & & - & & - & \\
\hline Happy most of the time & 0.96 & (0.86 to 1.08$)$ & 0.90 & (0.81 to 1.02$)$ & 0.94 & (0.84 to 1.06$)$ \\
\hline Unhappy* & 1.27 & (1.11 to 1.45$)$ & 1.01 & (0.88 to 1.16$)$ & 0.97 & (0.85 to 1.11$)$ \\
\hline \multicolumn{7}{|l|}{ Self-rated health } \\
\hline Fair/poor & (Referent) & & - & & - & \\
\hline Good & & & 0.61 & (0.53 to 0.69$)$ & 0.71 & (0.62 to 0.80$)$ \\
\hline Very good & & & 0.49 & (0.44 to 0.56$)$ & 0.63 & (0.55 to 0.71$)$ \\
\hline Excellent & & & 0.34 & (0.30 to 0.38 ) & 0.45 & (0.39 to 0.51 ) \\
\hline Male sex & & & & & 1.57 & (1.44 to 1.72$)$ \\
\hline \multicolumn{7}{|l|}{ Race/ethnicity } \\
\hline White & & & & & (Referent) & \\
\hline Black & & & & & 1.07 & (0.93 to 1.23 ) \\
\hline Hispanic & & & & & 0.94 & (0.80 to 1.11$)$ \\
\hline Other non-Hispanic race & & & & & 1.09 & (0.86 to 1.38$)$ \\
\hline Married & & & & & 0.83 & (0.75 to 0.91$)$ \\
\hline Current smoker & & & & & 1.92 & (1.73 to 2.14$)$ \\
\hline Education & & & & & 0.93 & (0.89 to 0.97$)$ \\
\hline \multicolumn{7}{|l|}{ Work force status } \\
\hline Out of work & & & & & 1.54 & (1.34 to 1.78$)$ \\
\hline Never worked & & & & & 1.71 & (1.34 to 2.18$)$ \\
\hline Retired & & & & & 1.38 & (1.19 to 1.60$)$ \\
\hline Own home & & & & & 0.82 & (0.74 to 0.92$)$ \\
\hline
\end{tabular}

Model 1 is stratified by 5 year age cohort. Model two adds self-rated health as a covariate. Model three adds to Model two sex, race/ethnicity, marital status, smoking (yes, no), education, workforce status and home tenure (own vs rent/other).

Data source: U.S. National Centre for Health Statistics.

*Unhappy was defined as happy none, a little, and some of the time.

models $\left(\mathrm{HR}_{\text {good }} 0.71 ; 95 \%\right.$ CI 0.62 to $0.80 ; \mathrm{HR}_{\text {very good }} 0.63$; $95 \%$ CI 0.55 to $0.71 ; \mathrm{HR}_{\text {excellent }} 0.45 ; 95 \%$ CI 0.39 to 0.51 ; table 3) and for women and men separately (table 4). HR estimates in the full sample were very similar when excluding persons who died within either 1 or 3 years of the baseline interview (data not shown). In addition, happiness was not associated with mortality within self-rated health categories whereas self-rated health remained strongly associated with mortality risk within happiness categories (figure 1).

Findings using the aggregated subjective well-being variable were similar to the happiness analyses. Well-being was inversely associated with mortality in the model stratifying on age cohort and smoking (HR 0.98; 95\% CI 0.97 to 0.98 ) but this association was reduced when adjusting for self-rated health (HR 0.99; 95\% CI 0.99 to 1.00 ) and sociodemographic variables (HR 1.00; $95 \%$ CI 0.99 to 1.00) (online supplementary table 1 ). This pattern was also observed when examining men and women separately (online supplementary table 2). Fully adjusted hazards were similar for a well-being index that included only happiness and life satisfaction (HR 0.99; 95\% CI 0.96 to 1.01) and the same pattern of HR attenuation was observed when evaluating life satisfaction and negative affect by themselves (online supplementary table 3 ).

When substituting the planned covariates for selfrated health in model 2, we found that although each of these also reduced the unhappiness HRs, the hazards for being unhappy remained statistically significant when adjusting for each of these singleton covariates (table 5). Rather than infer differences in hazards based on differences in significance tests, ${ }^{21}{ }^{22}$ we directly compared the unhappiness HR adjusted for self-rated health with the unhappiness HRs adjusted for each of the seven covariates individually. Self-rated health adjusted unhappiness HRs were significantly smaller than those adjusting for sex, race/ethnicity, being married, education and home ownership but were not different from hazards adjusted for either smoking or work force status (table 5). These patterns suggest that self-rated health attenuates the 
Table 4 Sex-specific happiness and all-cause mortality HRs (95\% Cl) before and after adjustment for self-rated health and sociodemographic variables

\begin{tabular}{|c|c|c|c|c|c|c|}
\hline \multirow[b]{2}{*}{ Women } & \multicolumn{2}{|l|}{ Model 1} & \multicolumn{2}{|c|}{ Model 2} & \multicolumn{2}{|l|}{ Model 3} \\
\hline & HR & $95 \% \mathrm{Cl}$ & HR & $95 \% \mathrm{Cl}$ & HR & $95 \% \mathrm{CI}$ \\
\hline \multicolumn{7}{|l|}{ Happiness } \\
\hline Happy all of the time & (Referent) & & & & & \\
\hline Happy most of the time & 1.05 & (0.90 to 1.22$)$ & 1.01 & (0.87 to 1.18$)$ & 1.03 & (0.88 to 1.20$)$ \\
\hline Unhappy* & 1.34 & (1.11 to 1.61$)$ & 1.12 & (0.93 to 1.35$)$ & 1.03 & (0.85 to 1.24$)$ \\
\hline \multicolumn{7}{|l|}{ Self-rated health } \\
\hline Fair/poor & (Referent) & & - & & - & \\
\hline Good & & & 0.62 & (0.52 to 0.73$)$ & 0.69 & (0.58 to 0.83 ) \\
\hline Very good & & & 0.50 & (0.42 to 0.59$)$ & 0.59 & (0.50 to 0.71$)$ \\
\hline Excellent & & & 0.43 & (0.36 to 0.52$)$ & 0.54 & (0.44 to 0.66$)$ \\
\hline \multicolumn{7}{|l|}{ Race/ethnicity } \\
\hline White & & & & & (Referent) & \\
\hline Black & & & & & 0.98 & (0.82 to 1.18$)$ \\
\hline Hispanic & & & & & 0.89 & (0.71 to 1.12$)$ \\
\hline Other non-Hispanic race & & & & & 1.58 & (1.11 to 2.25$)$ \\
\hline Married & & & & & 0.84 & (0.74 to 0.95$)$ \\
\hline Current smoker & & & & & 1.98 & (1.70 to 2.31$)$ \\
\hline Education & & & & & 0.92 & (0.87 to 0.98$)$ \\
\hline \multicolumn{7}{|l|}{ Work force status } \\
\hline Working & & & & & (Referent) & \\
\hline Out of work & & & & & 1.65 & (1.37 to 1.99$)$ \\
\hline Never worked & & & & & 1.78 & (1.34 to 2.38$)$ \\
\hline Retired & & & & & 1.54 & (1.27 to 1.88$)$ \\
\hline \multicolumn{3}{|l|}{ Own home } & & & 0.83 & (0.72 to 0.95$)$ \\
\hline \multirow[b]{2}{*}{ Men } & \multicolumn{2}{|l|}{ Model 1} & \multicolumn{2}{|c|}{ Model 2} & \multicolumn{2}{|l|}{ Model 3} \\
\hline & HR & $95 \% \mathrm{CI}$ & HR & $95 \% \mathrm{Cl}$ & HR & $95 \% \mathrm{Cl}$ \\
\hline \multicolumn{7}{|l|}{ Happiness } \\
\hline Happy all of the time & (Referent) & & & & & \\
\hline Happy most of the time & 0.91 & (0.77 to 1.09$)$ & 0.83 & (0.69 to 0.99$)$ & 0.84 & (0.70 to 1.00$)$ \\
\hline Unhappy & 1.29 & (1.04 to 1.59$)$ & 0.96 & (0.77 to 1.18$)$ & 0.88 & (0.71 to 1.10$)$ \\
\hline \multicolumn{7}{|l|}{ Self-rated health } \\
\hline Fair/poor & (Referent) & & - & & - & \\
\hline Good & & & 0.59 & (0.48 to 0.71$)$ & 0.71 & (0.58 to 0.87$)$ \\
\hline Very good & & & 0.48 & (0.40 to 0.59$)$ & 0.65 & (0.53 to 0.81$)$ \\
\hline Excellent & & & 0.26 & (0.21 to 0.32$)$ & 0.36 & (0.29 to 0.45$)$ \\
\hline \multicolumn{7}{|l|}{ Race/ethnicity } \\
\hline White & & & & & (Referent) & \\
\hline Black & & & & & 1.17 & (0.96 to 1.44$)$ \\
\hline Hispanic & & & & & 1.00 & (0.80 to 1.24$)$ \\
\hline Other non-Hispanic race & & & & & 0.75 & (0.52 to 1.10$)$ \\
\hline Married & & & & & 0.81 & (0.70 to 0.93$)$ \\
\hline Current smoker & & & & & 1.88 & (1.61 to 2.20$)$ \\
\hline Education & & & & & 0.93 & (0.87 to 0.99$)$ \\
\hline
\end{tabular}


Table 4 Continued

\begin{tabular}{|c|c|c|c|c|c|c|}
\hline \multirow[b]{2}{*}{ Men } & \multicolumn{2}{|c|}{ Model 1} & \multicolumn{2}{|c|}{ Model 2} & \multicolumn{2}{|c|}{ Model 3} \\
\hline & HR & $95 \% \mathrm{Cl}$ & HR & $95 \% \mathrm{Cl}$ & HR & $95 \% \mathrm{Cl}$ \\
\hline Working & & & & & \multicolumn{2}{|c|}{ (Referent) } \\
\hline Never worked & & & & & 1.89 & (1.08 to 3.28$)$ \\
\hline Retired & & & & & 1.19 & (0.97 to 1.47 ) \\
\hline
\end{tabular}

Model one is stratified by 5 year age cohort. Model two adds self-rated health as a covariate. Model three adds to Model two race/ethnicity, marital status, smoking (yes, no), education, workforce status and home tenure (own vs rent/other).

Sample sizes are 14084 and 11055 for women and men, respectively.

Data source: United States National Centre for Health Statistics.

*Unhappy was defined as being happy none, a little, or some of the time.

happiness/mortality association more so than important sociodemographic mortality determinants but is comparable to other mortality risk markers.

\section{DISCUSSION}

In a racially and ethnically diverse sample representing 164.9 million US adults without cardiovascular disease or cancer, we found that the association of unhappiness with 14-year mortality risk is eliminated when statistically controlling for self-rated health. These results closely replicate a very large study of UK women ${ }^{1}$ and extend them to US men and women. These findings parallel other population-based studies. ${ }^{23}{ }^{24}$ A more comprehensive index of well-being including life satisfaction, happiness and negative emotions was associated with all-cause mortality but this association was also statistically eliminated when adjusting for self-rated health and SES. More broadly, these patterns suggest that the apparent survival advantage for high well-being, as measured by happiness or by a comprehensive well-being index, is driven by established health risk markers.

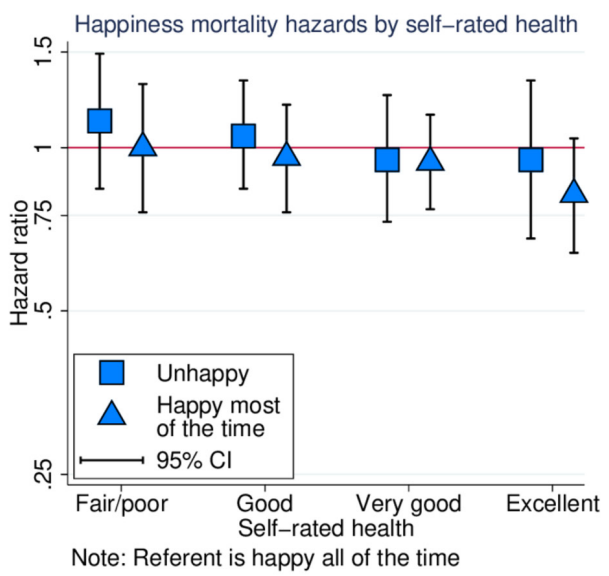

A meta-analysis that found an association between wellbeing and mortality also reported '...strong evidence for publication bias and small study effects." Thus, larger studies such as reported here should be especially diagnostic for this question. In addition, inadequate control of health status is a limitation of prior work ${ }^{4}$ which we addressed through selection of initially healthy participants and by using sensitivity tests excluding participants with early mortality. Other strengths of the present study include multiple well-being operations, long follow-up and a representative sample of US adults. Conversely, this study is limited in that another well-being facet, meaning and purpose in life, was not included. There is evidence this facet is independently associated with mortality ${ }^{25-27}$ and thus our conclusions are limited to happiness, life satisfaction and negative affect. Our work also does not address the potential bidirectional association of socioeconomic indicators such as workforce status and home ownership with subjective well-being.

Self-rated health and subjective well-being are both important health-related quality of life indicators ${ }^{28}$ that

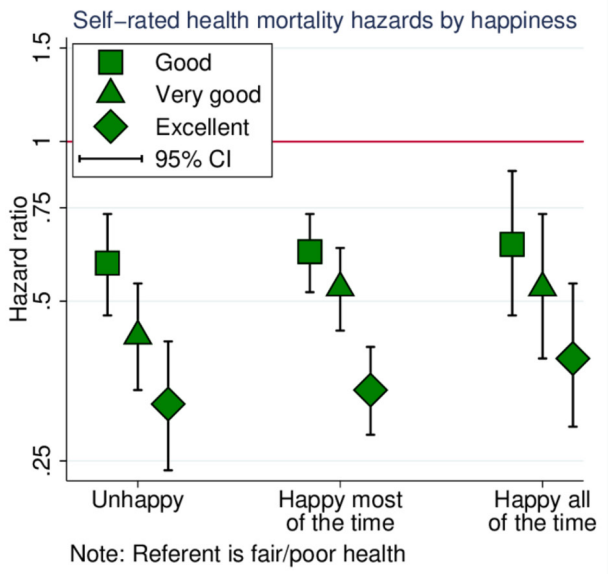

Figure 1 All-cause mortality HRs for happiness within self-rated health and self-rated health within happiness note: analyses stratify on 5-year age cohorts. 
have utility irrespective of their association with survival. However, there is greater certainty regarding the prognostic value of self-rated health for mortality. ${ }^{29} 30$ Additionally, self-rated health is tightly linked with established disease pathways such as 10-year cardiovascular disease risk $^{31}$ and improves mortality risk prediction in combination with coronary artery calcium scores. ${ }^{32}$ This study adds to a large body of evidence that a single question regarding perceived health is strongly predictive for survival. These data also indicate that other mortality determinants attenuate the happiness/mortality association, with smoking and work force status being the strongest. In sum, as in the largest study to date ${ }^{1}$ we found no robust association of any type of well-being measure with mortality after adjusting for established health determinants.

Contributors SDB conceptualised the study and analysed the data. SDB, TWB, MVE and TSL contributed to the literature search, wrote portions of the manuscript and provided critical feedback on the manuscript. All authors approved the final submission.

Funding This research was partially funded by the Southwest Health Equity Research Collaborative NIH/NIMHD \#U54MD012388.

Disclaimer The views expressed here do not reflect the views of the National Center for Health Statistics. The funders had no role in the writing of the manuscript or the decision to submit for publication.

Competing interests None declared.

Patient consent for publication Not required.

Provenance and peer review Not commissioned; externally peer reviewed.

Data availability statement Data are available in a public, open access repository. Dataset is publicly available from the US National Center for Health Statistics.

Open access This is an open access article distributed in accordance with the Creative Commons Attribution Non Commercial (CC BY-NC 4.0) license, which permits others to distribute, remix, adapt, build upon this work non-commercially, and license their derivative works on different terms, provided the original work is properly cited, appropriate credit is given, any changes made indicated, and the use is non-commercial. See: http://creativecommons.org/licenses/by-nc/4.0/.

ORCID iD

Steven D Barger http://orcid.org/0000-0002-8296-0974

\section{REFERENCES}

1 Liu B, Floud S, Pirie K, et al. Does happiness itself directly affect mortality? the prospective UK Million women study. The Lancet 2016;387:874-81.

2 The Lancet . Health and happiness. The Lancet 2016;387.

3 Zaninotto P, Wardle J, Steptoe A. Sustained enjoyment of life and mortality at older ages: analysis of the English longitudinal study of ageing. BMJ 2016;355.

4 Martín-María N, Miret M, Caballero FF, et al. The impact of subjective well-being on mortality: a meta-analysis of longitudinal studies in the general population. Psychosom Med 2017;79:565-75.

5 Diener E. Subjective well-being. The science of happiness and a proposal for a national index. Am Psychol 2000;55:34-43.

6 Atkinson T. The stability and validity of quality of life measures. Soc Indic Res 1982;10:113-32.

7 Rushton JP, Brainerd CJ, Pressley M. Behavioral development and construct validity: the principle of aggregation. Psychol Bull 1983;94:18-38.

8 Michalos AC, Maurine Kahlke P, Maurine KP. Stability and sensitivity in perceived quality of life measures: some panel results. Soc Indic Res 2010;98:403-34.

9 Centers for Disease Control and Prevention. Data file documentation, National health interview survey, 2001 (machine readable data file and documentation). Hyatsville, Maryland: National Center for Health Statistics, Centers for Disease Control and Prevention, 2002. https:// www.cdc.gov/nchs/nhis/about_nhis.htm 
10 Centers for Disease Control and Prevention. About the National Health Interview Survey [February 11,, 2019. Available: https://www. cdc.gov/nchs/nhis/about_nhis.htm [Accessed February 11, 2019].

11 Centers for Disease Control and Prevention. 2001 National Health Interview Survey (NHIS) Public Use Data Release: NHIS Survey Description., 2003. Available: ftp://ftp.cdc.gov/pub/Health_Statistics/ NCHS/Dataset Documentation/NHIS/2001/Srvydesc.pdf

12 National Center for Health Statistics.. Office of Analysis and Epidemiology, Public-use linked mortality file, 2019., 2019. Available: https://www.cdc.gov/nchs/data-linkage/mortality-public.htm [Accessed February 1, 2019].

13 Kessler RC, Barker PR, Colpe LJ, et al. Screening for serious menta illness in the general population. Arch Gen Psychiatry 2003;60:184-9.

14 Cologne J, Hsu WL, Abbott RD, et al. Proportional hazards regression in epidemiologic follow-up studies: an intuitive consideration of primary time scale. Epidemiology 2012;23:565-73.

15 Thiébaut ACM, Bénichou J. Choice of time-scale in Cox's model analysis of epidemiologic cohort data: a simulation study. Stat Med 2004;23:3803-20.

16 Pencina MJ, Larson MG, D'Agostino RB. Choice of time scale and its effect on significance of predictors in longitudinal studies. Stat Med 2007;26:1343-59.

17 Korn EL, Graubard BI, Midthune D. Time-to-event analysis of longitudinal follow-up of a survey: choice of the time-scale. Am J Epidemiol 1997;145:72-80.

18 Long JS, Freese J. Regression models for categorical dependent variables using Stata. 2nd ed. College Station, tx: Stata press 2006.

19 Barger SD, Donoho CJ, Wayment HA. The relative contributions of race/ethnicity, socioeconomic status, health, and social relationships to life satisfaction in the United States. Qual Life Res 2009;18:179-89.

20 Curtin SC, Arias E. Mortality trends by race and ethnicity among adults aged 25 and over, 2000-2017. NCHS data brief, no 342, 2019 Available: https://www.cdc.gov/nchs/data/databriefs/db342-h.pdf [Accessed 9 Sep 2019].

21 Gelman A, Stern $H$. The difference between "significant" and "not significant" is not itself statistically significant. Am Stat 2006;60:328-31.
22 Kaufman JS, MacLehose RF. Which of these things is not like the others? Cancer 2013;119:4216-22.

23 Stavrova O. Having a happy spouse is associated with lowered risk of mortality. Psychol Sci 2019;30:798-803.

24 Wiest M, Schüz B, Webster N, et al. Subjective well-being and mortality revisited: differential effects of cognitive and emotional facets of well-being on mortality. Health Psychology 2011;30:728-35.

25 Cohen R, Bavishi C, Rozanski A. Purpose in life and its relationship to all-cause mortality and cardiovascular events. Psychosom Med 2016;78:122-33.

26 Sone T, Nakaya N, Ohmori K, et al. Sense of life worth living (ikigai) and mortality in Japan: Ohsaki study. Psychosom Med 2008;70:709-15.

27 Tanno K, Sakata K, Ohsawa M, et al. Associations of ikigai as a positive psychological factor with all-cause mortality and causespecific mortality among middle-aged and elderly Japanese people: findings from the Japan collaborative cohort study. J Psychosom Res 2009;67:67-75.

28 Office of Disease Prevention and Health Promotion. Healthrelated quality of life \& well-being, 2019. Available: https://www. healthypeople.gov/2020/topics-objectives/topic/health-relatedquality-of-life-well-being [Accessed 26 Mar 2019].

29 Ganna A, Ingelsson E. 5 year mortality predictors in 498103 UK Biobank participants: a prospective population-based study. The Lancet 2015;386:533-40. .https://doi.org/

30 Idler EL, Benyamini Y. Self-Rated health and mortality: a review of twenty-seven community studies. J Health Soc Behav 1997;38:21-37.

31 Barger SD, Cribbet MR, Muldoon MF. Participant-Reported health status predicts cardiovascular and All-Cause mortality independent of established and nontraditional biomarkers: evidence from a representative US sample. J Am Heart Assoc 2016;5:e003741.

32 Orimoloye OA, Mirbolouk M, Uddin SMI, et al. Association between self-rated health, coronary artery calcium scores, and atherosclerotic cardiovascular disease risk: the multi-ethnic study of atherosclerosis (MESA). JAMA Netw Open 2019;2:e188023. 